\title{
Prevalence of Drugs as Triggers of Exacerbations in Chronic Urticaria
}

\author{
Sánchez J1,2, Sánchez $A^{1,2,3}$, Cardona $\mathrm{R}^{1,2}$ \\ ${ }^{1}$ Group of Clinical and Experimental Allergy, IPS Universitaria, University of Antioquia, Medellin, Colombia \\ ${ }^{2}$ Foundation for the Development of Medical and Biological Sciences (FUNDEMEB), Cartagena, Colombia \\ ${ }^{3}$ Faculty of Medicine, Corporation University Rafael Nunez, Cartagena, Colombia
}

J Investig Allergol Clin Immunol 2019; Vol. 29(2): 112-117

doi: 10.18176/jiaci.0287

\begin{abstract}
Background: Many patients with chronic spontaneous urticaria (CSU) report various drugs as triggers of their symptoms and often avoid medication unnecessarily.

Objective: To estimate the clinical impact of the drugs patients most frequently suspect of inducing CSU exacerbations.

Methods: The prevalence of self-reported drug reactions was evaluated by questioning patients about their clinical history of urticaria and drug reactions and performing challenge tests with the suspect drugs. A group of healthy persons were included as controls to evaluate the prevalence of self-reported drug reactions.

Results: The study population comprised 245 patients with CSU and 127 healthy individuals. At least 1 adverse drug reaction was reported by $92(37.5 \%)$ patients and 30 (23.6\%) controls. Nonsteroidal anti-inflammatory drugs (NSAIDs) (27.7\%) and B-lactams (9.4\%) were the most commonly reported drugs in the CSU group and the control group, respectively. Positive results in the challenge tests were less common than self-reports in the CSU group (13\%) and the control group $(0.7 \%)$.

Conclusion: Self-reporting is generally not sufficient to confirm a drug reaction. Drug reactions to NSAIDs and B-lactams are more frequent among patients who experience CSU than in those who do not. Drug challenge tests should be offered early during medical evaluation to avoid unnecessary restrictions.
\end{abstract}

Key words: Urticaria. Angioedema. Drugs. Aspirin. NSAIDs. Atopy. Oral challenge.

\section{Resumen}

Antecedentes: Muchos pacientes con urticaria crónica espontánea (CSU, por sus siglas en inglés) informan que varios medicamentos son desencadenantes de sus síntomas y, a menudo, evitan dichos medicamentos de forma innecesaria.

Objetivo: Estimar el impacto clínico en la CSU de los fármacos que los pacientes sospechan con mayor frecuencia como causantes de exacerbaciones.

Métodos: Se evaluó la prevalencia de las reacciones a los fármacos autoinformadas al interrogar a los pacientes y se realizó pruebas de desafío con los fármacos sospechosos. Se incluyó un grupo de personas sanas como controles para evaluar la prevalencia de las reacciones a los fármacos autoinformadas.

Resultados: La población del estudio comprendió 245 pacientes con CSU y 127 individuos sanos. 92 (37,5\%) pacientes y 30 (23,6\%) controles informaron al menos 1 reacción adversa al medicamento. Los fármacos antiinflamatorios no esteroideos (AINE) (27,7\%) y las B-lactámicos $(9,4 \%)$ fueron los fármacos informados con mayor frecuencia en el grupo CSU y el grupo control, respectivamente. Los resultados positivos en las pruebas de desafío fueron menos comunes que los autoinformes en el grupo CSU ( $13 \%$ ) y el grupo control (0,7\%). Conclusión: La autoinformación generalmente no es suficiente para confirmar una reacción al fármaco. Las reacciones de los medicamentos a los AINE y los B-lactámicos son más frecuentes entre los pacientes que experimentan CSU que en los que no lo hacen. Las pruebas de detección de drogas deben ofrecerse temprano durante la evaluación médica para evitar restricciones innecesarias.

Palabras clave: Urticaria. Angioedema. Medicamentos. Aspirina. AINE. Atopia. Reto oral. 


\section{Introduction}

Urticaria is a common cutaneous disease. The chronic form affects around $1 \%$ of the general population and has a significant impact on quality of life. Since chronic spontaneous urticaria (CSU) can appear at any time, patients frequently report foods, drugs, and various activities as possible causes of exacerbations [1,2]. Avoidance of suspicious medication by patients has implications for clinical management. In acute urticaria, drugs may play a causal role, although in chronic forms, the role of medications is not so clear [3].

Some studies have evaluated how often the triggers reported by the patient are actually associated with symptoms. We previously observed that the prevalence of self-reported inducible urticaria was $75 \%$, although the prevalence confirmed in positive challenge tests was only $36 \%$, indicating that a high number of patients avoid allergens unnecessarily [4]. Between $20 \%$ and $50 \%$ of patients report that nonsteroidal antiinflammatory drugs (NSAIDs) are the agents most commonly associated with exacerbations in CSU. The 2018 GA2LEN/ WAO/EAACI guidelines recommend avoidance of suspected triggers, including drugs such as NSAIDs. Consequently, if the patient is taking drugs that might exacerbate CSU, then they should be discontinued. However, unless an objective evaluation is carried out, the restrictions may be unnecessary and worsen quality of life [5,6]. Challenge tests are required to confirm a clear relationship. However, most studies evaluating the prevalence of drugs as a cause or trigger of chronic urticaria do not include this approach. In fact, few studies apply objective diagnostic tests to evaluate the clinical impact of drugs as triggers of urticaria in CSU patients. Sanchez et al [7] used oral challenges with acetylsalicylic acid (ASA) and observed that $12 \%$ of patients with chronic urticaria had NSAIDs-exacerbated cutaneous disease. The comparison between self-reported data and challenge test results suggests that self-reporting cannot confirm drugs as triggers of CSU. In addition, while the prevalence of NSAIDs as triggers of CSU has been evaluated, there is less information about the role of other drugs.

In this study, we explore the prevalence of various drugs as triggers of urticaria in patients with CSU, taking into account self-reported data and the challenge test result. We also compared this frequency with that of a control group of individuals without CSU.

\section{Methods}

\section{Study Population}

We conducted a multicenter, prospective study based on a previously described cohort (URTICA project, ClinicalTrials. gov Identifier: NCT01940393). Recruitment of patients was open, and patients from 6 clinical centers participated. We collected data from patients aged $\geq 12$ years diagnosed with CSU, which was defined as recurrence of hives with or without angioedema on more than 3 days per week and persisting for at least 6 weeks. The exclusion criteria included the following: systemic disease that could explain the hives; use of systemic corticosteroids during the 3 weeks before recruitment; and immunodeficiency, dermatitis, and/or any other disease that could alter the results of the skin test.

A control group of people without CSU from the University of Antioquia, Medellin, Colombia aged $\geq 12$ years and with no previous history of chronic urticaria were invited to participate in order to enable us to compare the results of questionnaires and challenge tests. In the control group, the participants answered a questionnaire about drug reactions, and challenge tests were performed in those patients who reported an adverse reaction other than a clear history of anaphylaxis or a severe drug reaction (eg, drug rash with eosinophilia and systemic symptoms and toxic epidermal necrolysis).

\section{Study Design}

The aim of the study was to report epidemiological data on possible triggering factors of urticaria exacerbations among patients with CSU. First, both groups were questioned about adverse drug reactions (ADRs). Second, drugs suspected by patients or controls of being triggers of urticaria exacerbations were directly assessed using challenge tests. After 1 year, we asked patients who self-reported drug reactions and had a negative challenge test result if they had used the medication.

\section{Evaluation of Drug Reactions With Challenge Tests}

The oral challenge test was blind and placebo-controlled. Challenge tests with drugs reported by the patients $(\geq 1$ per patient) were performed using the same protocol, namely, the equivalent to 1 daily dose of the drug was administered in 2 doses (10\% and 90\%, respectively) separated by 1 hour. In patients with suspected severe reactions (eg, anaphylaxis or respiratory distress), the administration of the daily dose was divided into 4 steps $(10 \%, 20 \%, 30 \%$, and $40 \%$, respectively) separated by 1 hour. After the final dose was administered, the patient remained under observation at the clinic for 2 hours and was instructed to report delayed reactions outside the clinic. The same protocol was applied for all challenge tests unless the protocols published in the medical literature suggested any major changes for a specific drug.

Patients with a clear anaphylactic reaction within 1 hour of consuming the suspected drugs 12 months before recruitment were considered to have a positive result and the challenge test was obviated. Anaphylactic reactions without a clear clinical history or any other type of reaction were confirmed by challenge test.

The result of the challenge was considered positive only if the patient experienced objective symptoms involving the skin or other system. If the patient had an unclear reaction after the first administration of the medication, the treating physician divided the following dose into a maximum of 4 doses with an interval of 1 hour between administrations.

\section{Statistical Analyses}

Statistical analyses were performed using IBM SPSS Statistics for Windows, Version 21.0 (IBM Corp). Descriptive variables were reported as mean (SD). The differences between proportions were analyzed using Pearson's $\chi^{2}$ test. Given the sample size of previous studies that evaluated the presence of drug reactions in patients with CSU, we considered that a 
Table 1. General Characteristics of the Study Population

\begin{tabular}{lccc}
\hline Characteristics & CSU group (n=245) & Control group (n=127) & $P$ \\
\hline Age, y & $28(14-50)$ & $27(15-55)$ & $>.05$ \\
Female sex, No. (\%) & $150(61)$ & $79(62)$ & $>.05$ \\
History of drug skin reaction (\%) & $92(37)$ & $30(23)$ & .04 \\
Time since drug reaction, mo & $9(3-24)$ & $14(6-36)$ & $>.05$ \\
Atopy, No. (\%) & $105(42)$ & $37(29)$ & .04 \\
Asthma, No. $(\%)$ & $36(14)$ & $5(3)$ & .05 \\
Rhinitis, No. $(\%)$ & $105(42)$ & $50(39)$ & NA \\
Age of onset CSU, y & $25(4-49)$ & NA & NA \\
Mean (SD) DLQI score & $15(3)$ & NA & NA \\
Mean (SD) UAS & $3(1)$ & NA \\
\hline
\end{tabular}

Abbreviations: CSU, chronic spontaneous urticaria; DLQI, Dermatology Life Quality Index; NA, not applicable; UAS, Urticaria Activity Score.

sample of at least 150 patients would be adequate to guarantee a power of $90 \%$ and an $\alpha$ error of 0.05 for measurement of the primary outcome. A $P$ value of $<.05$ was considered statistically significant.

\section{Results}

\section{General Characteristics}

A total of 245 patients with CSU (CSU group) and 127 healthy controls participated in this study (Table). Atopy and asthma were significantly more frequent in patients with CSU than in the control group $(P<.05)$. In both groups, more than $20 \%$ of the participants reported adverse skin reactions with 1 drug at some point in their life ( $37.5 \%$ vs $23.6 \%$, respectively; $P=.04$ ). This percentage was higher in the CSU group. The average time between the ADR and the performance of the challenge test was lower in the CSU group ( 9 months vs 14 months), although the difference was not statistically significant $(P=.07)$. No other differences in general characteristics were observed between the CSU group and the control group. During the recruitment phase, the patients' mean Urticaria Activity Score (UAS) was 3 (1); the score was $>2$ points in $68 \%$ of patients, indicating that urticaria was active.

\section{Self-Reported Adverse Drug Reactions}

The most common drugs reported (92 patients in the CSU group and 30 in the control group) were as follows (Figure 1): NSAIDs (68 [73.9\%] patients vs 10 [33.3\%] patients, respectively), $\beta$-lactams (28 [30.4\%] vs 12 [40\%]), and natural medicines ( $8[8.6 \%]$ vs 0$)$, which included over-the-counter herbal products. The most frequently reported NSAIDs were ASA $(n=24)$, ibuprofen $(n=24)$, and meloxicam $(n=20)$; the most frequently reported $\beta$-lactam was amoxicillin. In the CSU group, $64 \%$ of patients with ADRs to NSAIDs reported at least 2 different drugs.

"Other drugs" were more frequently reported in patients with CSU. Eighteen patients self-reported adverse reactions

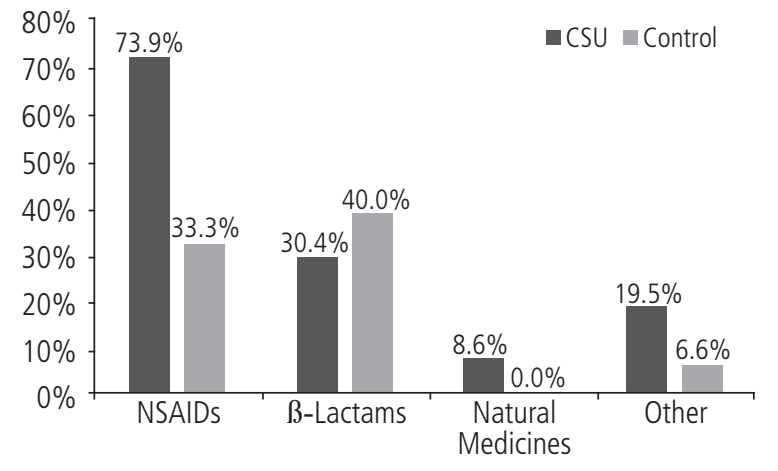

Figure 1. Self-reporting of adverse drug reactions. Medications most frequently reported by patients with CSU and the control group. CSU indicates chronic spontaneous urticaria; NSAID, nonsteroidal antiinflammatory drug.

with 2 drugs from unrelated groups, 3 with 3 pharmacological agents, and 2 with more than 3 . All participants with a selfreport of ADRs restricted the suspicious drug, and $45 \%$ restricted other drugs not associated with the clinical history of reactions. The main reasons for these restrictions were "doctor's orders" (33\%) and "fear" (28\%).

Two patients had a clear history of urticaria 6 months prior to enrollment and were considered positive without an oral challenge test. The remaining patients with suspected ADRs underwent a challenge test.

\section{Challenge Tests and Their Association With Self- Reported Reactions}

Of the total number of individuals in each group (245/127), 32 patients $(13 \%)$ had a positive challenge test result in the CSU group compared with 1 in the control group $(0.7 \%)$ (Figure 2A). Cutaneous reactions were the most frequent $(n=27)$, followed by respiratory reactions $(n=7)$. Two patients had lower respiratory and skin symptoms and required treatment with epinephrine. 
A

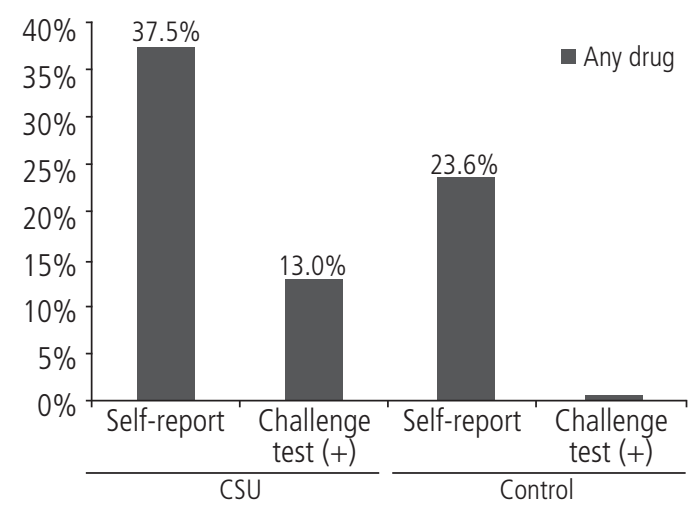

B

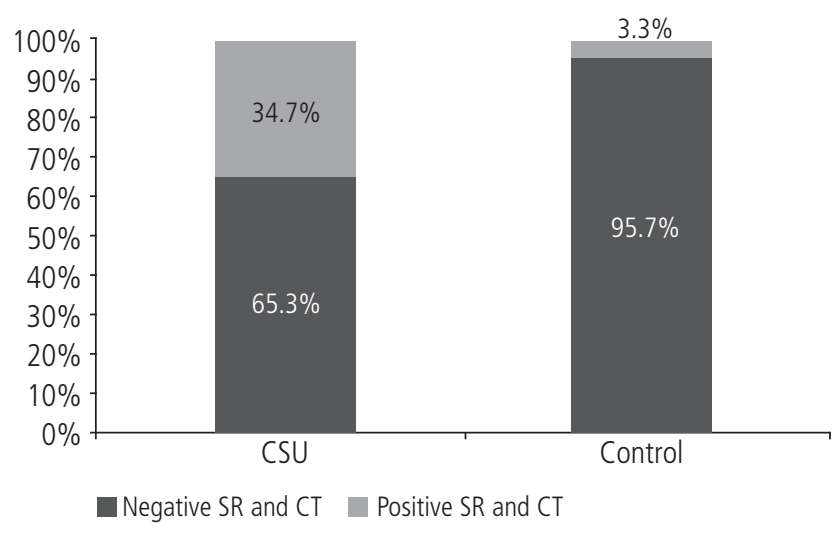

Figure 2. Comparison of self-reported data and challenge test results among patients with CSU and the control group. A, Frequency calculated according to the total number of participants in each group (247/127). B, Self-reported data in each group (92/30) and challenge test results: negative (black) and positive (gray). CSU indicates chronic spontaneous urticaria; SR, self-reported; CT, challenge tests.

Agreement between self-reported results and positive challenge tests results was better in the CSU group than in the controls (Figure 2B).

Among patients with history of ADRs with NSAIDs (68 with CSU vs 10 in the control group), 28 CSU patients (41.1\%) had a positive challenge test result compared with 0 in the control group.

One individual from the control group (10\%) and 12 patients from the CSU group (42.8\%) presented a positive challenge test result with amoxicillin. There were no positive challenge test results for "natural medicines" in either of the groups.

When evaluating which factors could influence the results, we observed that, in contrast with the control group, atopy was more frequent in individuals with positive challenge test results in the CSU group (OR, 3.14: 95\%CI, 1.18-4.29; $P=.03$ ). Differences for other factors such as age, gender, and age at onset of the disease were not statistically significant.

\section{Follow-up}

Thirty patients had an indication to consume the medication; 22 consumed it without problems, one patient reported an intestinal reaction, and another a cutaneous reaction (erythema), although both continued taking the medication for the indicated time. Six patients did not consume it because they were afraid to, despite the negative test result.

\section{Discussion}

Patients with CSU commonly associate onset of symptoms with activities they were performing [4] or medications [1] or foods [8] that they were consuming near the time of the reaction. Avoidance of suspicious medications by patients has implications for clinical management. Frequent use of drugs such as NSAIDs has been paralleled by increasingly frequent adverse reactions, which vary from mild local skin rashes or gastric irritation to severe, generalized symptoms and even life-threatening anaphylaxis [9]. Although NSAIDs have been recognized as a frequent cause of exacerbation among patients with chronic or acute urticaria $[7,10]$, the actual incidence by objective assessments such as challenge testing remains unclear. In addition, the effect of other medications as triggers in patients with CSU is practically unknown [11].

Consistent with our previous findings for inducible urticaria [4], we recorded a high frequency of self-reported ADRs among both CSU patients and controls. We found that 1 out of every 3 patients with self-reported ADR had a positive challenge test result, compared with fewer than 1 in 10 persons in the control group. The low concordance between the selfreport and the provocation test in both groups suggests that it is necessary to confirm self-reported data through controlled tests to avoid unnecessary restrictions.

Despite the low association between self-reported data and challenge test data, patients with urticaria had a much higher frequency of reactions than the control group, not only for NSAIDs, but also for ß-lactams. Sanchez et al [12], observed an association between self-reported ADRs and higher levels of total IgE and mite-specific IgE. Although many studies suggest that the pathophysiological mechanisms underlying skin reactions to NSAIDs differ from those responsible for common allergic (atopic) diseases [7,13,14], the high prevalence of atopy and asthma observed in patients with CSU in the present study is puzzling, as was the case in the study by Sánchez et al. Equally noteworthy is the observation by Kim et al [15] that patients with aspirin-exacerbated acute and chronic urticaria had a higher prevalence of atopy and total serum IgE. The reasons for this association between atopy and urticaria and ADR are not known, although in some patients, the development of atopy may share mechanisms with the development of hypersensitivity to medications. Synthesis of leukotrienes could be a common route for both these processes to develop. Several lines of evidence have suggested an interaction between IgE-mediated immune responses and the leukotriene pathway, for example, the proximity between the genes encoding $\mathrm{IgE}$ and leukotrienes [16] and the association between leukotrienes and hypersensitivity reactions that can affect the lung, such as NSAID-exacerbated respiratory 
disease [17]. However, the role of leukotrienes in urticaria is controversial, and this hypothesis does not clearly explain the association we found between atopy and reactions to medications other than NSAIDs, such as ß-lactams.

An additional question that may arise from the association between atopy and urticaria and ADRs is whether atopic individuals or those with a history of ADR may have an increased risk of developing CSU. We do not know the answer to this question. According to Doña et al [18], who performed a 12-year follow-up of 190 patients with NSAIDinduced urticaria/angioedema, the risk of developing CSU is no greater than in the control group, although other authors report different results $[19,20]$.

Consumption of over-the-counter products for the management of diseases is quite common in Colombia. While many of these products can produce nonspecific degranulation of mast cells and development of acute urticaria [21], participants from both groups in our study who consumed them tolerated the challenge test.

Our study is subject to a series of limitations. Because the challenge tests were only performed in the population with self-reported ADRs, the number of adverse reactions may be underestimated, since some participants had not consumed the reported medications and others had consumed them more than a year previously. Therefore, we cannot rule out the possibility that they currently experience ADRs, especially in the CSU group. However, from the clinical point of view, participants who do not have a history of ADRs, including patients with $\mathrm{CSU}$, have no contraindications to any medication. Therefore, it is not necessary for them to undergo challenge testing. Although challenge testing is the gold standard for determining the association between exposure and immediate symptoms, conducting a challenge test does not ensure $100 \%$ tolerance to new exposures; an increase in the dose delivered could lead to a reaction not detected during the test. In any case, challenge testing remains the most objective method for evaluating a reaction to a medication. Additionally, of the 24 patients who consumed the medication on an outpatient basis, 22 tolerated it without problems, and the 2 who reported mild reactions completed the course of medications.

Our results suggest a high frequency of reactions to NSAIDs (33\%) among the population with urticaria; however, other studies suggest a lower frequency $(12 \%)$ [12]. Therefore, it is necessary to perform multicenter studies to consider other factors that may underlie these differences.

Among the strengths of our study is the use of a control group to evaluate the frequency of self-reporting and the performance of challenge tests with the suspect medication for each participant. When trying to compare our results with those of other studies with a similar design in the CSU population, we found that most focused on patients with acute urticaria and made the diagnosis based on self-reported data. Furthermore, in almost all cases they evaluated the role of NSAIDs but not that of other medications such as ß-lactams.

In conclusion, self-reported data are usually not sufficiently reliable to confirm an ADR, and challenge tests must be offered early during the medical evaluation to avoid unnecessary restrictions. Pharmacological reactions to NSAIDs and ß-lactams in patients with CSU are more frequent than in individuals without urticaria.

\section{Acknowledgments}

We thank Dr. Javier Estarita and Dr. Carolina Salemi for their collaboration in the clinical follow-up of patients.

\section{Funding}

This study was sponsored by the Clinical and Experimental Allergy Group of the University of Antioquia, Medellín, Colombia.

\section{Conflicts of Interest}

The authors declare that they have no conflicts of interest.

\section{References}

1. Thomsen SF, Pritzier EC, Anderson CD, Vaugelade-Baust $\mathrm{N}$, Dodge $\mathrm{R}$, Dahlborn $A K$, et al. Chronic urticaria in the real-life clinical practice setting in Sweden, Norway and Denmark: baseline results from the non-interventional multicentre AWARE study. J Eur Acad Dermatol Venereol. 2017:31(6):1048-55.

2. Sánchez-Borges $M$, Caballero-Fonseca $F$, Capriles-Hulett A. Cofactors and comorbidities in patients with aspirin/ NSAID hypersensitivity. Allergol Immunopathol (Madr). 2017;45(6):573-8.

3. Magerl M, Altrichter S, Borzova E, Giménez-Arnau A, Grattan $C E$, Lawlor $F$, et al. The definition, diagnostic testing, and management of chronic inducible urticarias - The EAACI/ GA(2) LEN/EDF/UNEV consensus recommendations 2016 update and revision. Allergy. 2016;71(6):780-802.

4. Sánchez J, Amaya E, Acevedo A, Celis A, Caraballo D, Cardona R. Prevalence of Inducible Urticaria in Patients with Chronic Spontaneous Urticaria: Associated Risk Factors. J Allergy Clin Immunol Pract. 2017;5(2):464-70.

5. Zuberbier T, Aberer W, Asero R, Bindslev-Jensen C, Brzoza Z, Canonica GW, et al. The EAACl/GA(2) LEN/EDF/WAO Guideline for the definition, classification, diagnosis, and management of urticaria: the 2013 revision and update. Allergy. 2014;69(7):868-87.

6. Zuberbier $T$, Aberer W, Asero R, Abdul Latiff AH, Baker D, Ballmer-Weber $B$, et al. The EAACI/GA2LEN/EDF/WAO Guideline for the Definition, Classification, Diagnosis and Management of Urticaria. The 2017 Revision and Update. Allergy. 2018;73(7):1393-414.

7. Sánchez-Borges $M$, Caballero-Fonseca $F$, Capriles-Hulett $A$, González-Aveledo L. Aspirin-exacerbated cutaneous disease (AECD) is a distinct subphenotype of chronic spontaneous urticaria. J Eur Acad Dermatol Venereol. 2015;29(4):698-701.

8. Chung BY, Cho YS, Kim HO, Park CW. Food Allergy in Korean Patients with Chronic Urticaria. Ann Dermatol. 2016;28(5):562-8.

9. Kowalski ML, Makowska JS. Seven steps to the diagnosis of NSAIDs hypersensitivity: how to apply a new classification in real practice? Allergy Asthma Immunol Res. 2015;7(4):31220.

10. Sánchez-Borges M. NSAID hypersensitivity (respiratory, cutaneous, and generalized anaphylactic symptoms). Med Clin North Am. 2010;94(4):853-64, xiii. 
11. Balakirski G, Merk HF. Cutaneous allergic drug reactions: update on pathophysiology, diagnostic procedures and differential diagnosic. Cutan Ocul Toxicol. 2017;36(4):307-16.

12. Sánchez-Borges M, Acevedo N, Caraballo L, CaprilesHulett A, Caballero-Fonseca F. Increased total and mitespecific immunoglobulin $E$ in patients with aspirin-induced urticaria and angioedema. J Investig Allergol Clin Immunol. 2010;20(2):139-45.

13. Simons FE, Ardusso LR, Dimov V, Ebisawa M, El-Gamal YM, Lockey RF, et al. World Allergy Organization Anaphylaxis Guidelines: 2013 Update of the Evidence Base. Int Arch Allergy Immunol. 2013;162(3):193-204.

14. Sánchez J, Sánchez A. Epidemiology of food allergy in Latin America. Allergol Immunopathol (Madr). 2015;43(2):185-95.

15. Kim HA, Ye YM, Kim SH, Hur GY, Park HS. Association of beta 2-adrenergic receptor polymorphism with the phenotype of aspirin-intolerant acute urticaria. Yonsei Med J. 2007;48(6):1079-81.

16. Acevedo N, Mercado D, Vergara C, Sánchez J, Kennedy MW, Jiménez $\mathrm{S}$, et al. Association between total immunoglobulin $\mathrm{E}$ and antibody responses to naturally acquired Ascaris lumbricoides infection and polymorphisms of immune systemrelated LIG4, TNFSF13B and IRS2 genes. Clin Exp Immunol. 2009;157(2):282-90.

17. Liu T, Barrett NA, Kanaoka Y, Yoshimoto E, Garofalo D, Cirka $\mathrm{H}$, et al. Type 2 Cysteinyl Leukotriene Receptors Drive IL-33Dependent Type 2 Immunopathology and Aspirin Sensitivity. J Immunol. 2018;200(3):915-27.
18. Doña I, Blanca-López N, Torres MJ, Gómez F, Fernández J, Zambonino MA, et al. NSAID-induced urticaria/angioedema does not evolve into chronic urticaria: a 12-year follow-up study. Allergy. 2014;69(4):438-44.

19. Asero R. Multiple nonsteroidal anti-inflammatory druginduced cutaneous disease: what differentiates patients with and without underlying chronic spontaneous urticaria? Int Arch Allergy Immunol. 2014;163(2):114-8.

20. Asero R. Intolerance to nonsteroidal anti-inflammatory drugs might precede by years the onset of chronic urticaria. J Allergy Clin Immunol. 2003;111(5):1095-8.

21. Meincke R, Pokladnikova J, Straznicka J, Meyboom RHB, Niedrig D, Russmann $S$, et al. Allergy-like immediate reactions with herbal medicines in children: A retrospective study using data from VigiBase. Pediatr Allergy Immunol. 2017;28(7):66874.

\section{Manuscript received April 24, 2018; accepted for publication June 19, 2018.}

\section{- Jorge Sánchez}

E-mail: jorgem.sanchez@udea.edu.co jotamsc@yahoo.com 